\title{
Employee Engagement Level and Its Key Determinants: a Study in the Context of Nepalese Media Sector
}

\author{
Damodar Niraula, M.Phil. \\ Nesfield International College \\ Email: damodarniraula@gmail.com
}

\begin{abstract}
This paper aims to measure the level of employee engagement and to propose employee engagement framework. Following two-step sampling method, a questionnaire survey was conducted among the employees of fifteen media houses. The results of the survey are analyzed with the help of SPSS 18 version. Majority of the employees of Nepalese media houses have been found being engaged to their job. The findings confirm that five HR practices: performance appraisal and recognition; participatory culture; working facility; communication; and job and resources are the determinants of employee engagement. Among those, performance appraisal and recognition, and participatory culture, should be the major focus of human resource managers to make the employees engaged. Additionally, the paper can serve as a reference and an analytical tool to researchers for expanding knowledge on the topic.
\end{abstract}

Keywords: Employee engagement, engagement determinants, media sector

\section{Background}

According to Gallup Incorporation (2017), engagement is the state at which employees become emotionally and psychologically attached to their work and workplace. Engaged employees employ and express themselves physically, cognitively, and emotionally during role performances. In other words, attaching employees' hand, head, and heart is employee engagement. A highly engaged employee consistently delivers beyond expectation (Soni, 2013). To get success in business, the traditional approaches commonly used by organizations concentrate on output increment, control cost and providing leverage in workplace. However, due to some limitations of those means, the target of the authority shifted toward human resource management (HRM). Rather than focusing on reducing costs, the shift of the focus in HRM is to build employee engagement (Bakar, 2013). Many researches 
have proved that the higher level of employee engagement positively reflects on productivity and other business performance outcomes (Markos \& Sridevi, 2010; Macey \& Schneider, 2008; Vance, 2006; Gallup Incorporation, 2017; Baumruk \& Gorman, 2006; Lockwood, 2007; Aon, 2012; Towers Watson, 2012). Similarly, one can find a number of engagement measurement models developed, tested and suggested by researchers (Kahn, 1990; Schaufeli, Salanova, Gonzalez-Roma, \& Bakker, 2002; Towers Watson, 2012; GP Strategies, 2013; Vance, 2006; Gallup Incorporation, 2017; Aon, 2011; Yuan \& Lee, 2011).

Measuring employee engagement level and categorizing them into different types is a complex and confusing work. Harter, Schmidt, Killham, \& Asplund (2006) mentions that the $\mathrm{Q}^{12}$ model developed by Gallup Consulting for measuring employee engagement is widely used throughout the world. By identifying engagement determinants, measuring engagement level and classifying employees accordingly into different groups, an organization can develop and implement HRM programs, organizational plans and policies which lead to the business success. With this caveat in mind, this paper focuses on two objectives: i) to measure the level of employee engagement, and ii) to propose employee engagement framework for Nepalese media sector.

\section{Theoretical Background}

Engagement is a case of give and take - of gaining satisfaction and giving contribution (GP Strategies, 2013). Employee engagement is a business concept. The words 'work engagement' and 'employee engagement' are often interchangeably used. However, according to Jeve, Oppenheimer, and Konje (2015), work engagement is employee's commitment towards work at individual level, and employee engagement is the process at organizational level. Even though the concept of employee engagement has been heavily used by consulting firms, it is new to academic field. Though the term engagement was first conceptualized and defined by Kahn, the term employee engagement, as a construct, coined by the Gallup Organization (Ologbo \& Sofian, 2013).

Kahn (1990) defined engagement as personal engagement. It is the simultaneous employment and expression of a person's "preferred self" in task behaviors that promote connections to work and to others, personal presence (physical, cognitive, and emotional), and active, full role performances. He further describes engagement as the sum of meaningfulness, safety, and availability which an engaged employee experiences. 
Employee engagement can best be defined as a positive, fulfilling, work-related state of mind that is characterized by vigor, dedication and absorption (Schaufeli et. al., 2002). Robinson, Perryman, and Hayday (2004) defined employee engagement as a positive attitude held by the employee towards the organization and its value. An employee with positive attitude is aware of business context, and works with colleagues to improve performance. In this regard, role of the organization is to develop and nurture engagement by establishing a two-way relationship between employer and employee.

Engagement is a workplace approach designed to ensure that employees are committed to their organizations' goals and values, motivated to contribute to organizational success, and are able at the same time to enhance their own sense of well-being (MacLeod \& Clarke, 2009). It is a positive attitude toward the job (Rothwell, 2010); the willingness to invest oneself and expand one's discretionary effort to help the employer succeed, which is beyond simple satisfaction with the employment arrangement or basic loyalty to the employer (Sharma \& Krishnan, 2012; Karsan \& Kruse, 2011); a holistic experience perceived and then interpreted through the lens of each individual based on their own experience, rationales and views of their context (Shuck, Rocco, \& Albornoz (2011); the state of commitment and energy that employees bring to work and a key indicator of employees' involvement and dedication to the organization (Truss, Shantz, Soane, Alfes, \& Delbridge 2013).

Baniya (2004) urged that positive consequences of providing development oppourtunities to employees of Nepalese manufaturing enterprises are improved performance, increased productivity, enhanced loyalty, and increased motivation. In a study of human resource practices and organizational performance of Nepalese banking sector, Pandey (2011) concluded that four HR practices including decentralization, compensation policy, information sharing, and job security have positive relation with employee satisfaction; five HR practices including training \& development with earlier four components influence the commitment level to the employees; and six HR practices including selective hiring with earlier five components have positive relation with productivity. Similarly, Chaulagain \& Khadka (2012) observed opportunity to develop, responsibility, patient care and staff relations have a significance influence on job satisfaction among the healthcare professionals at Tilganga Eye Care Centre, Kathmandu, Nepal. 
Consequently, companies with higher level of employee engagement accomplish something that competitors will find very difficult to imitate (Macey \& Schneider, 2008), and there is positive relationship between employee engagement and organizational performance outcomes: employee retention, productivity, profitability, customer loyalty and safety (Markos \& Sridevi, 2010). The greater an employee's engagement, the more likely the employee is to "go the extra mile", deliver excellent on-the-job performance, helps an organization to achieve mission, execute strategy and generate important business results as well as more likely to commit to staying with the current organization (Vance, 2006) because of their strong emotional connection to their organizations (Gallup Incorporation, 2017).

According to Baumruk and Gorman (2006), as cited by Markos and Sridevi (2010), engaged employee consistently demonstrates three general behaviours which improve organizational performance:

- Say-the employee advocates for the organization to co-workers, and refers to potential employees and customers

- Stay-the employee has an intense desire to be a member of the organization despite opportunities to work elsewhere

- Strive-the employee exerts extra time, effort and initiative to contribute to the success of the business

In measuring the level of employee engagement, Kahn (1990) identified three different psychological conditions that explore the role of employees are: meaningfulness, safety, and availability.

Kahn emphasizes employees unconsciously ask themselves three questions in each situation and make themselves engage or disengage depending on the answer and the questions are; how meaningful is it for me to bring myself into this performance?; how safe is it to do so?; and how available am I to do so? Kahn advocates sense of meaningfulness makes employees feel worthwhile, valued, valuable; feel able to give to and receive from work and others in course of work. Similarly, consequences of sense of safety are that employees feel situations are trustworthy, secure, predictable, and clear in terms of behavioral consequences, and the sense of availability makes employees feel capable of driving physical, intellectual, and emotional energies into role performance. 
Schaufeli et. al. (2002) observed employee engagement is characterized by vigor, dedication, and absorption. Vigor is characterized by high levels of energy and mental resilience while working, the willingness to invest effort in the work and persistence even in the face of difficulties. Personnel with vigor are characterized as a highly engaged employee. Vigor refers to an individual's feeling that they possess physical strength, emotional energy and cognitive liveliness. It refers to an affective state that individuals attribute to their job and workplace. Vigor in this respect focuses on the notion of having 'energy' at work. However, it does not refer to behavioral responses to events at work such as dedication to work, which is a significant characteristic of employee engagement. The second element, dedication, refers to being strongly involved in one's work and experiencing a sense of significance, enthusiasm, inspiration, pride and challenge (Schaufeli et. al., 2002). Meanwhile, absorption describes the feeling of contentment while performing work. Absorption represents a state of being fully concentrated on and happily engrossed in work, a state in which time passes quickly and one has difficulty in detaching oneself from work (Bakar, 2013). Schaufeli and Bakker (2003) also confirmed absorption as a relevant aspect of engagement.

Similarly, Towers Watson (2010) defined engagement along three dimensions: Rational: How well employees understand their roles and responsibilities Emotional: How much passion they bring to the work and their organizations Motivational: How willing they are to invest discretionary effort to perform roles well

Towers Watson (2012) expanded the concept of employee engagement to sustainable engagement; and described the term sustainable engagement as the intensity of employees' connection to their organization, based on three core elements:

- The extent of employees' discretionary effort committed to achieving work goals (being engaged)

- An environment that supports productivity in multiple ways (being enabled)

- A work experience that promotes well-being (feeling energized)

In the similar type work, Bakar (2013) used the following factors to measure employee engagement in his work:

1. At my job, I feel strong and vigorous.

2. When I get up in the morning, I feel like going to work.

3. I can continue working for very long periods at a time. 
4. At my job, I am very mentally resilient.

5. My job inspires me.

6. I am proud of the work I do.

7. To me, my job is challenging.

8. I find the work that I do full of meaning and purpose.

9. I am enthusiastic about my job.

10. I am immersed in my work.

11. Time flies when I am working.

12. I feel happy when I am working intensely.

13. It is difficult to detach myself from my job.

Being 'present at work' requires a particular mental state. In order to be engaged, an individual has to think, feel and act on their job. In other words, this mental state constitutes a driving force which requires physical, cognitive and emotional resources (Bakar, 2013).

According to GP Strategies (2013), engaged employees are not just committed. They are not just passionate or proud. They have a line-of-sight on their own future and on the organization's mission and goals. They are enthused and in gear, using their talents and discretionary effort to make a difference in their employer's quest for sustainable business success.

Kahn (1990) stated that there are altogether eleven influencers of engagement dimensions. Likewise, Vance (2006) urged for the job design, recruitment, selection, training, compensation, and performance management for the enhancement of employee engagement. While, Gallup Incorporation is using the following twelve items, which is commonly known as $\mathrm{Q}^{12}$, to measure the level of employee engagement:

Q1. I know what is expected of me at work.

Q2. I have the materials and equipment I need to do my work right.

Q3. At work, I have the opportunity to do what I do best every day.

Q4. In the last seven days, I have received recognition or praise for doing good work.

Q5. My supervisor, or someone at work, seems to care about me as a person.

Q6. There is someone at work who encourages my development.

Q7. At work, my opinions seem to count.

Q8. The mission or purpose of my company makes me feel my job is important.

Q9. My associates or fellow employees are committed to doing quality work. 
Q10. I have a best friend at work.

Q11. In the last six months, someone at work has talked to me about my progress.

Q12. This last year, I have had opportunities at work to learn and grow.

Regarding the Nepalese organizations, Adhikari and Gautam (2011) found lack of interesting, challenging and motivating job results less engagement in the given work, and thus emphasize on the role of HR professionals and departments especially to integrate HR and business strategies so as to make people motivated, committed and engaged. Aon (2011) revealed the top three engagement drivers; career opportunities, brand alignment, and recognition. In the 'Aon Hewitt's Engagement Model', it has included six engagement drivers; work, people, opportunities, total rewards, company practices, and quality of life. In Global Workforce Study Report 2012, Towers Watson has mentioned the top five drivers of sustainable engagement (Table 1).

Table 1

Engagement Dimensions Prescribed by Towers Watson

\begin{tabular}{ll}
\hline Priority areas of focus & Behaviors and actions that matter to employees \\
\hline Leadership & $\begin{array}{l}\text { Is effective at growing the business } \\
\text { Shows sincere interest in employees' well-being } \\
\text { Behaves consistently with the organization's core values } \\
\text { Earns employees' trust and confidence }\end{array}$ \\
\hline $\begin{array}{l}\text { Stress, balance and } \\
\text { workload }\end{array}$ & $\begin{array}{l}\text { Manageable stress levels at work } \\
\text { Enough employees in the group to do the job right } \\
\text { Flexible work arrangements }\end{array}$ \\
\hline Goals and objectives & $\begin{array}{l}\text { Employees understand: } \\
\text { The organization's business goals } \\
\text { Steps they need to take to reach those goals } \\
\text { How their job contributes to achieving goals }\end{array}$ \\
\hline Supervisors & $\begin{array}{l}\text { Assign tasks suited to employees' skills } \\
\text { Act in ways consistent with their words } \\
\text { Coach employees to improve performance } \\
\text { Treat employees with respect }\end{array}$ \\
\hline Organization's image & $\begin{array}{l}\text { Highly regarded by the general public } \\
\text { Displays honesty and integrity in business activities }\end{array}$ \\
\hline
\end{tabular}


All of those engagement dimensions and drivers have been tried to incorporate in this study. All the dimensions are arranged in thirty statements in the employee survey questionnaire. Among those, nine statements are related to measure employee engagement level and the rest twenty-one are used as the employee engagement influencers.

At Tilganga Eye Care Centre, Kathmandu, Nepal, 13.33\% of healthcare professionals are highly satisfied, $62.67 \%$ are satisfied, and the rest $24 \%$ are not satisfied (Chaulagain \& Khadka, 2012). Following engagement criterion, Kahn (1990) classified employees into two types; personally engaged and personally disengaged. In his words, personally engaged employees are those who physically involved in tasks, whether alone or with others, cognitively vigilant, and empathically connected to others in the service of the work they are doing in ways that display what they think and feel, their creativity, their beliefs and values, and their personal connections to others, and keep their selves within a role without sacrificing one for the other. Conversely, personally disengaged employees withdraw and defense their preferred self in behaviors that promote a lack of connections, physical, cognitive, and emotional absence, and passive, incomplete role performances.

According to Yuan and Lee (2011), as sited in AbuKhalifeh and Mat Som (2013), there are three groups of employees; engaged employees, not engaged employees, and actively disengaged employees. Firstly, the "Engaged Employees" are those who are ardent about their job and, have a sense of personal responsibility and obligation to what they should do to their company. Secondly, the "Non Engaged Employees" are those employees who do not have the energy during the performance of their job. Lastly, the "Actively Disengaged Employees" are those who are unhappy with their job, always try to let everyone know that, and constantly keep trying to make those engaged employees disengaged.

Towers Watson (2012) classified the surveyed employees into four categories; highly engaged, unsupported, detached, and disengaged. It has further revealed that $35 \%$ of global workforce is highly engaged, while $22 \%$ are unsupported, $17 \%$ are detached, and $26 \%$ are disengaged.

GP Strategies (2013) classified employee engagement into five levels; the engaged, almost engaged, honeymooners \& hamsters, crash \& burners, and the disengaged. Classification is based on employees' contribution and satisfaction level. The most wanted level that every organization should try to achieve is "The Engaged". 
During the year 2014 and 2016, 15\% of employees worldwide were engaged in their job. Majority of employees i.e. $67 \%$, were not engaged and remaining $18 \%$ were actively disengaged employees (Gallup Incorporation, 2017). Gallup Incorporation defines these categories as follows: engaged employees are those are highly involved in and enthusiastic about their work and workplace, psychological owners, initiate performance and innovation and thus move the organization forward. Those employees who are psychologically unattached to their work and company; they have no energy or passion into their work-just passing their time at workplace have been classified into not engaged employees. Actively disengaged employees are unhappy at work, they share their unhappiness with others and also try to detach their engaged coworkers from their work.

\section{Research Methodology}

This research attempts to measure employee engagement level and classifies them into either of the categories; engaged, not engaged, or actively disengaged. The basic assumption laid here is employee engagement is considered as the result of different human resource practices adopted and practiced by organization.

It follows two-step sampling method. Media organizations are selected following purposive sampling method, and employees working in those organizations are selected following convenient sampling method.

Fifteen national daily newspaper, 30 Radio/FM and 12 televisions registered in Kathmandu district are taken as the population of this study. Further, employees working in those 57 organizations are taken as population of the respondents of this research. A total of 15 organizations (5 Newspaper, 6 Radio/FM, 4 Television) incorporating private and public from all three media modes and 326 employees working in those organizations are selected as sample of the research.

This study incorporates qualitative aspects of employees. By using a set of questionnaire, primary data relating to employee perception on employee engagement and its determinants are collected from employees of media houses. Survey questionnaire contains thirty statements with four-point Likert-type scale ranging from 1 (strongly disagree) to 4 (strongly agree).

All the media houses are personally visited by the researchers. Of the fifteen media houses, employees available in their respective job stations and ready to respond the survey questionnaire are randomly selected and distributed the survey questionnaire to them. In this way, a total of 326 questionnaires are distributed. The questionnaires 
$10 \mid$ THE BATUK : A Peer Reviewed Journal of Interdisciplinary Studies Vol. 6 Issue No.1 Jan 2020 ISSN 2392-4802

are collected as far as at the same time as well as following on the time given by the respondents.

For the analysis of data, SPSS 18 version is used. Data is analyzed by using descriptive statistics, reliability analysis, factor analysis, correlations analysis, regression analysis, independent sample t test and ANOVA test.

\section{Results}

Out of 326 questionnaires distributed, a total of 262 are returned and among those, eighteen survey responses are found to be incomplete as well as multiple responses and thus dropped. In this way, a total of 244 responses are used for the analysis (74.85 per cent response rate).

\section{Result i: Level of Employee Engagement}

Cronbach's Alpha of the employee engagement variables is found to be 0.724 . The highest value is 0.720 (My work directly contributes to the overall success of the organization) and the lowest is 0.670 (At my job, I feel strong and energetic).

Table 2

Mean Ranking of the Engagement Variables

\begin{tabular}{lll}
\hline Variables & Mean & $\begin{array}{l}\text { Std. } \\
\text { Deviation }\end{array}$ \\
\hline I help others in this organization whenever I can. & 3.44 & 0.56 \\
I personally feel accountable for my performance. & 3.37 & 0.611 \\
My work directly contributes to the overall success of the & 3.36 & 0.65 \\
organization. & & \\
I know what is expected of me at work. & 3.31 & 0.538 \\
At my job, I feel strong and energetic. & 3.25 & 0.701 \\
To me, my job is challenging. & 3.2 & 0.744 \\
My ideas and opinions count at work. & 3.12 & 0.763 \\
Time flies when I am working. & 2.97 & 0.734 \\
It is difficult to detach myself from my job. & 2.77 & 0.766 \\
Average & 3.199 & 0.674 \\
\hline
\end{tabular}

Average response of employees on engagement variables is 3.199 with standard deviation of 0.674 . The variable "I help others in this organization whenever I can" has the highest mean score 3.440 with standard deviation of 0.560 and the least 
score is 2.77 with 0.766 standard deviation of the variable "It is difficult to detach myself from my job" (Table 2).

Employees with more than 3 mean score on engagement are classified as engaged employees. Those employees scoring between the range of 2 and 3 are categorized as not engaged employees and the rest are classified as actively disengaged. In Nepalese media sector, 65.60 per cent of the employees are engaged, 0.40 per cent is actively disengaged, and the rest 34 per cent are not engaged (Table 3 ).

Table 3

Types of Employees of Media Sector

\begin{tabular}{llll}
\hline Type of Employees & Frequency & Per cent & Mean \\
\hline Actively Disengaged & 1 & 0.4 & 2 \\
Not Engaged & 83 & 34 & 2.8046 \\
Engaged & 160 & 65.6 & 3.4111 \\
Total & 244 & 100 & 3.199 \\
\hline
\end{tabular}

\section{Result ii: Factors Influencing Employee Engagement}

Using the reliability and factor analysis criterion, only 18 engagement influencing variables are retained with 0.838 value of Cronbach's Alpah. The highest Cronbach's Alpha value is 0.838 (I am satisfied with my job) and the lowest is 0.824 of the variable (Employee performance evaluations are fair and appropriate).

Engagement influencing variables are grouped into five factors. Five factors altogether explained 63.88 per cent of the total variance. According to the nature of variables associated with, five factors are named as follows; performance appraisal and recognition, participatory culture, working facility, communication, and job and resources (Table 4). Average responses of employees regarding engagement influencing factors are $2.872,2.792,2.76,2.73$, and 2.99 respectively. 
Table 4

Naming of the Factors

\begin{tabular}{|c|c|c|}
\hline Factors & Variables & Factor's Name \\
\hline Factor 1 & $\begin{array}{l}\text { My senior always treats me with respect. } \\
\text { My senior always cares me and my job. } \\
\text { I receive the praise and recognition I deserve. } \\
\text { Employee performance evaluations are fair and appropriate. } \\
\text { I receive feedback that helps me improve my performance. } \\
\text { My job provides me the chance of personal growth and } \\
\text { development. }\end{array}$ & $\begin{array}{l}\text { Performance } \\
\text { appraisal and } \\
\text { recognition }\end{array}$ \\
\hline Factor 2 & $\begin{array}{l}\text { I am comfortable sharing my opinions at work. } \\
\text { People trust each other in my work group. } \\
\text { I have best friends at work. } \\
\text { People in my work group cooperate with each other to get } \\
\text { the job done. } \\
\text { People in my work group quickly resolve conflicts when } \\
\text { arise. }\end{array}$ & $\begin{array}{l}\text { Participatory } \\
\text { culture }\end{array}$ \\
\hline Factor 3 & $\begin{array}{l}\text { My workplace is physically comfortable to work. } \\
\text { Movement of people at my work place does not disturb me } \\
\text { and my work. } \\
\text { My working environment is exciting to work. }\end{array}$ & Working facility \\
\hline Factor 4 & $\begin{array}{l}\text { I get regular information about the mission and the goals of } \\
\text { this organization. } \\
\text { I am kept well informed about the changes in the } \\
\text { organization that affect my job. }\end{array}$ & Communication \\
\hline Factor 5 & $\begin{array}{l}\text { I have sufficient materials and information I need to do my } \\
\text { job well. } \\
\text { I am satisfied with my job. }\end{array}$ & $\begin{array}{l}\text { Job and } \\
\text { resources }\end{array}$ \\
\hline
\end{tabular}

The highest and the lowest correlation values between five factors are 0.284 and 0.07 with 0.000 and $0.277 \mathrm{sig}$ values respectively. The highest correlation is between performance appraisal and recognitions and job and resources and the least correlation is between working facility and job and resources. All five factors are correlated with employee engagement at 1 per cent level of significance. 
Table 5

Correlation Between Factors

\begin{tabular}{lllllll}
\hline Factors & $\begin{array}{l}\text { Factor } \\
1\end{array}$ & $\begin{array}{l}\text { Factor } \\
2\end{array}$ & $\begin{array}{l}\text { Factor } \\
3\end{array}$ & $\begin{array}{l}\text { Factor } \\
4\end{array}$ & $\begin{array}{l}\text { Factor } \\
5\end{array}$ & $\begin{array}{l}\text { Employee } \\
\text { Engagement }\end{array}$ \\
\hline Factor 1 & 1 & & & & & \\
Factor 2 & $.261^{* *}$ & 1 & & & & \\
Factor 3 & $.269 * *$ & $.280^{* *}$ & 1 & & & \\
Factor 4 & $.283^{* *}$ & $.263^{* *}$ & $.240^{* *}$ & 1 & & \\
Factor 5 & $.284^{* *}$ & $.195^{* *}$ & 0.07 & $.183^{* *}$ & 1 & \\
Employee & $.393^{* *}$ & $.373^{* *}$ & $.343^{* *}$ & $.171^{* *}$ & $.202 * *$ & 1 \\
Engagement & & & & & & \\
\hline
\end{tabular}

**. Correlation is significant at the 0.01 level (2-tailed).

The factor correlation matrix (Table 5) indicates that the factors leading to employee engagement identified by the study have minimum correlation that fulfils the requirement of factors to be independent. This minimizes the problem of autocorrelation. Regression model is found to be fit only with first three factors. The model revealed that the value of $\mathrm{R}$ square is 0.268 where value of $\mathrm{F}$ is 29.328 at 0.000 sig. value. Within the model, standardized beta coefficients of three factors are $0.275,0.246$ and 0.200 and the t-values are significant at 0.95 confidence level.

\section{Summary and Conclusion}

The study revealed that 65.60 per cent employees working in Nepalese media sector are engaged and 34 per cent of the employees are not engaged to their job. It also confirmed that employee engagement of Nepalese media sector primarily depends upon five HR practices: performance appraisal and recognition, participatory culture, working facility, communication, and job and resources. Among these, the performance appraisal and recognition ranks first.

The first factor, "performance appraisal and recognition", is similar as; tasks, and roles (Kahn, 1990), recruitment, selection, training, and performance management (Vance, 2006), opportunity, total reward, and company practices (Aon, 2011), supervisors, and leadership (Towers Watson, 2012), significance to recognize individuals' contribution, and excitement to constantly encourage - and raise the bar on - high performance (GP Strategies, 2013), individual and growth need (Gallup Incorporation, 2017). 
14 THE BATUK : A Peer Reviewed Journal of Interdisciplinary Studies $\quad$ Vol. 6 Issue No.1 Jan 2020 ISSN 2392-4802

Similarly, the second factor, "participatory culture", is alike to the factors; work interactions, interpersonal relationships, and group and intergroup dynamics (Kahn, 1990), people (Aon, 2011), organizaiton's image (Towers Watson, 2012), and community for a sense of belonging and purpose, and authenticity as a basis for trust and inspiration (GP Strategies, 2013), and teamwork needs (Gallup Incorporation, 2017).

The third factor, "working facility", is same as quality of life (Aon, 2011). The fourth factor ie. "communication" is comparable to the management style and process, and organizational norms as defined by Kahn (1990). At last, the factor "job and resources" is also identical to the factors; job design, and compensation (Vance, 2006), work (Aon, 2011), and basic needs (Gallup Incorporation, 2017).

Surprisingly, only 0.4 per cent of media sector employees are found actively disengaged. This may be due to industry specific feature. However, further research is needed to validate the result. To enhance the current understanding regarding engagement of Nepalese employees and to generalize the findings, studies including demographic variables are also necessary. Studies which include employees from other industries and establish relationship with organization's performances are expected to contribute a deeper understanding on the importance of employee engagement in Nepal and other likely countries.

\section{References}

AbuKhalifeh, A. N., \& Mat Som, A. P. (2013). The Antecedents Affecting Employee Engagement and Organizational Performance. Asian Social Science, 9 (7).

Adhikari, D. R., \& Gautam, D. K. (2011). Employees' commitment and organizational performance in Nepal: A typological framework. SEBON Journal, 1-17.

Aon, H. (2012). Trends in Global Employee Engagement. Retrieved from http://www.aon.com/humancapital-consulting/thoughtleadership/leadership/2012_Trends_in_Global_Employee_Engagement

Bakar, R. A. (2013, March). Understanding Factors Influencing Employee Engagement: A Study of the Financial Sector in Malaysia. Ph.D. Thesis.

Baniya, L. B. (2004). Human resource development practice in Nepalese business organizations: a case study of manufacturing enterprises in Pokhara. The Journal of Nepalsese Business Studies, I (1), 58-68. 
Chaulagain, N., \& Khadka, D. K. (2012). Factors influencing job satisfaction among healthcare pressionals at Tilganga Eye Care Centre, Kathmandu, Nepal. International Journal of Scientific \& Technology Research, 1 (11), 32-36.

Gallup Incorporation. (2017). State of the Global Workplace. Gallup Incorporation.

GP Strategies. (2013). Employee engagement research update. BlessingWhite. BlessingWhite.

Harter, J. K., Schmidt, F. L., Killham, E. A., \& Asplund, J. W. (2006). Q12® MetaAnalysis. Gallup Consulting.

Jeve, Y. B., Oppenheimer, C., \& Konje, J. (2015). Employee engagement within the NHS: a cross-sectional study. International Journal of Health Policy and Management, 4 (4).

Kahn, W. A. (1990). Psychological conditions of personal engagement and. Academy of Management Journal, 33 (4), 692-724.

Karsan, R., \& Kruse, K. (2011). We: How to Increase Performance and Profits through Full Engagement. Wiley \& Sons.

Lockwood, N. R. (2007). Leveraging Employee Engagement for Competitive Advantage: HR's Strategic Role. SHRM Research .

Macey, W., \& Schneider, B. (2008). The meaning of employee engagement. Industrial and Organizational Psychology: Perspectives on Science and Practice, 1 (1), 3-30.

MacLeod, D., \& Clarke, N. (2009). Engaging for Success: Enhancing Performance Through Employee Engagement. Office of Public Sector Informantion, London.

Markos, S., \& Sridevi, M. S. (2010). Employee Engagement: The Key to Improving Performance. International Journal of Business and Management, 5 (12), 8996.

Ologbo, A. C., \& Sofian, S. (2013). Individual and Organizational Factors of Employee Engagement on Employee Work Outcomes. International Journal of Business and Behavioral Sciences, 3 (3), 1-9.

Pandey, D. L. (2011). Human resource practices and organization performance: a study of Nepalese banking sector. Conference Proceedings, 1 (1), 379-390. Nepal Academy of Management.

Robinson, D., Perryman, S., \& Hayday, S. (2004). The Drivers of Employee Engagement Report. Institution for Employment Studies, UK.

Rothwell, N. (2010). The engaged university. A manifesto for public engagement. Retrieved from https://www.publicengagedment.ac.uk 
16I THE BATUK : A Peer Reviewed Journal of Interdisciplinary Studies $\quad$ Vol. 6 Issue No.1 Jan 2020 ISSN 2392-4802

Schaufeli, W. B., Salanova, M., Gonzalez-Roma, V., \& Bakker, A. B. (2002). The measurement of engagement and burnout: a two sample confirmatory factor analytic approach. Journal of Happiness Studies, 3 (1), 71-92.

Schaufeli, W., \& Bakker, A. (2003). Utrecht Work Engagement Scale Preliminary Manual. Occupational Health Psychology Unit, Utrecht University.

Sharma, D., \& Krishnan, V. R. (June 2012). The Impact of Pay Satisfaction and Transformational Leadership on Employee Engagement. 5th International Conference of Management and Behavioural Sciences. Haridwar, India.

Shuck, M. B., Rocco, T. S., \& Albornoz, C. A. (2011). Exploring employee engagement fromthe employee perspective: implications for HRD. Journal of European Industrial Training, 35 (4), 300-325.

Soni, B. S. (2013). Employee Engagement - A Key To Organizational Success In 21st Century. Voice of Research, 1 (4), 51-55.

Towers Watson. (2012). Global Workforce Study: Engagement at Risk: Driving Strong Performance in a Volatile Global Environment. Towers Watson.

Towers Watson. (2010). Turbocharging Employee Engagement: the Power of Recognition from Management. Part 1 - The Engagement Engine. Research Report. April 2009.

Truss, C., Shantz, A., Soane, E., Alfes, K., \& Delbridge, R. (2013). Employee engagement, organisational performance and individual well-being: exploring the evidence, developing the theory. The International Journal of Human Resource Management, 24 (14), 2657-2669.

Vance, R. J. (2006). Employee engagement and commitment: a guide to understanding, measuring and increasing engagement in your organization. Society of Human Resource Management (SHRM) Foundation. 